\title{
Effect of initial seawater concentration on forming ice slurry for thermal energy storage in fishing vessel
}

\author{
Fajri A Rayhan ${ }^{1}$, Yanuar ${ }^{1, *}$, and Agus $S$ Pamitran ${ }^{1}$ \\ ${ }^{1}$ Department Mechanical Engineering, Laboratory of Refrigeration, Universitas Indonesia, Kampus UI Depok 16424, Indonesia.
}

\begin{abstract}
Ice slurry technology has great potential in maximizing the chilling process of fish. Seawater is widely used as base solution of ice slurry due to Natrium Chloride content as freezing point depressant. In this study, effect of initial seawater concentration was investigated experimentally. The initial concentration of seawater was varied at 1, 1.5, 2, 2.5 and $3 \mathrm{wt} \%$, respectively. Performance of systems and microscopic of ice particles were also observed. Ice slurry generated from $1 \mathrm{wt} \%$ seawater solution gives good agreement toward formation time of ice slurry. The diameter of particle ice increases with decrease in concentration. For application in thermal energy storage of fishing vessel, it is recommended to use low concentration of seawater.
\end{abstract}

\section{Introduction}

In fishery industry, microbial mechanisms and biochemical give a big influence on decaying process of aquatic product [1]. The preservation methods play important role in reduce the deterioration of fish. Onboard fishing vessel, fish products urge a strong effect on the quality of manufactured products and consequence on commercial value $[2,3]$. There are many research projects in understanding of the chilling method to reduce the deterioration of fish physically and chemically [4-7] . hygienic handling and cooling method are key parameters to guaranteeing aquatic product and wholesomeness that must be combined optimally. In cooling method, refrigerated seawater (RSW) and/or different types of fresh ice are widely used for aquatic product. The cooling methods (RSW and fresh ice) have showed traditionally slow down microbial degradation mechanisms [8]. However, the method capable of damaging the fish texture and having poor heat transfer [9]. Newly, an engineered cooling method has allowed the storage of aquatic product at sub-zero temperature through the addition freezing point depressant to icewater mixtures and can prevent damaging the fish texture. These are called ice slurry or two-phases aqueous of secondary refrigerant.

Ice slurry is secondary refrigerant in solid-liquid phase where ice crystals distributed in water or an aqueous solution [10]. In cooling aquatic product, the ice crystals are made by freezing point depressant such as natrium chloride which is abundant substance in the ocean and brackish rivers. Currently, Ice slurry shows promising cooling method for the preservation of aquatic food products [11]. Ice slurry is the only one ice that can produce a pumpable ice mixture with small ice crystal particles [12]. The high flow rates and phase change offer exceptionally high heat transfer which proceed rapid cooling in aquatic product. these advantages being relevant in the case of soft tissues fish. Wang et al. [13] reported that ice slurry could improve cooling of aquatic product by utilizing properties such as:

- Ice temperature can be arranged as the cooling fish temperature;

- smooth surface of particle preventing fish from damage;

- close to isothermal of heat exchange during melt-off;

- easy mixing, forming, handling and pumping; Therefore, for the he optimum design of thermal energy storage systems for aquatic product by using ice slurry. The research of characteristics behaviour of two phase slurry is of high importance.

Melinder and Ignatowicz [14] examined properties of seawater to form ice slurry. They have investigated property data of seawater as function of salinity and temperature. An enthalpy-phase diagram and tables with ice concentration, enthalpy change and density of ice slurry. An enthalpy-phase diagram and tables with ice concentration, enthalpy change and density of ice slurry using seawater had been proposed by them. Pamitran et al. [15] reviewed application of ice slurry on Indonesian traditional fishing. They stated that Indonesia has big potential for utilization ice slurry system for fishery industry. Sari et al. [16] visualized ice particle by microscopic instrument. It was found that the shape of ice particles approximately ellipsoidal. Yanuar et al. [17] experimentally investigated that guar gum can give drag reduction effect for slurry flow. Hansen et al. [18] stated that geometrical shape of ice slurry is not effected by time significantly.

This study was carried out in order to investigate effect of seawater concentration/salinity. After forming

*Corresponding author: yanuar@eng.ui.ac.id 
ice slurry, the size and form of ice slurry is observed by microscope. An original feature of this study is observation effect of concentration on ice slurry formation time and on systems performance.

\section{Experimental setup}

\subsection{Experimental Apparatus}

Experimental setup designed and built at the laboratory of refrigeration, Universitas Indonesia consists of a vapor-compression system, a data acquisition system, an ice slurry generator, an ice storage tank, figure 1 . The main components of vapor-compression system are: the hermetic compressor, the condenser, the needle valve and the evaporator/ ice generator.

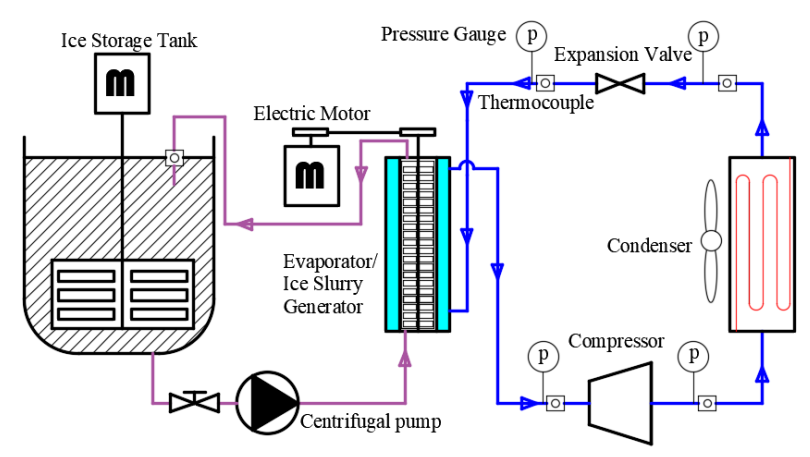

Fig 1. Schematic diagram of experimental apparatus

The refrigerant in vapor-compression systems was R290. Rayhan [19] reported that using R-290 on ice slurry system shows good performance. The low pressure of refrigerant was maintained manually by needle valve around 2-3 bar.

For purpose of this experiment, the measuring apparatus consisted of K-type thermocouples and pressure gauges that well insulated. Thermocouples had been calibrated in thermostatic bath with an accuracy of $0.1^{\circ} \mathrm{C}$. Refrigerant temperature and pressure was measured by four thermocouples and four pressure gauges that installed separately in four components of vapor-compression cycle. One thermocouple was inserted in ice storage tank. The list of measuring apparatus is summarized in table 1 .

Table 1. List of measuring apparatus

\begin{tabular}{|l|l|l|c|}
\hline \multicolumn{1}{|c|}{ Apparatus } & \multicolumn{1}{|c|}{ Type } & Range & Accuracy \\
\hline $\begin{array}{l}\text { Temperature } \\
\text { sensors }\end{array}$ & $\begin{array}{l}\text { K-type } \\
\text { thermocouples }\end{array}$ & $-50-500^{\circ} \mathrm{C}$ & $\pm 0,1^{\circ} \mathrm{C}$ \\
\hline $\begin{array}{l}\text { Pressure } \\
\text { gauge }\end{array}$ & Wika EN $837-1$ & $0-16$ bar & $\pm 0,1$ bar \\
\hline $\begin{array}{l}\text { Visualisation } \\
\text { instrument }\end{array}$ & $\begin{array}{l}\text { Digital } \\
\text { Microscope }\end{array}$ & $\begin{array}{l}1000 \mathrm{x} \\
\text { magnifier }\end{array}$ & - \\
\hline Power meter & $\begin{array}{l}\text { Mini Ammeter } \\
- \text { D02A }\end{array}$ & $0-3000 \mathrm{~W}$ & $\pm 1 \%$ \\
\hline $\begin{array}{l}\text { Data } \\
\text { Acquisition } \\
\text { Unit }\end{array}$ & $\begin{array}{l}\text { NI cDAQ - } \\
9174\end{array}$ & - & - \\
\hline
\end{tabular}

The ice generator is mechanical type with scraper. The scraper was driven by electric motor that equipped by inverter. The ice slurry is formed on the inner wall of generator and removed by means of the rotating scraper that placed in the middle of generator. The ice storage tank was separated from vapor-compression cycle. It could store $50 \mathrm{~L}$ of ice slurry. To keep the homogeneity of ice slurry, the agitator was installed in storage tank. The centrifugal pump was equipped with an inverter to control the flowrate of ice slurry. After formed ice slurry, it was observed by microscope as a shown in figure 2 .

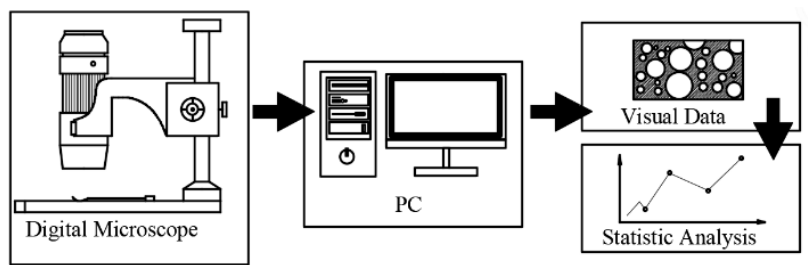

Fig 2. Layout of the simplified flow chart of the ice particles visualization

\subsection{Experimental Procedure}

The experimental study of ice slurry was carried out on the seawater with initial concentration 1, 1.5, 2, 2.5 and $3 \mathrm{wt} \%$, respectively. The test was conducted at ambient temperature ( 25 degree Celsius). Ice slurry was produced using a modified vapor-compression system. From aqueous solution until formed ice slurry, temperature and pressure of refrigerant was recorded in every minute. Scraper was running continuously to prevent agglomeration of ice in evaporator. Pump were running continuously to ensure homogeneity of ice slurry in storage tank. Variations flow rate of pump were 100, 120, 130 (cubic meter per minute). The speed of scraper was varied at 350, 450, 550 (RPM).

Ice particles generated from seawater were observed by digital microscope. Those average diameters were measured in PC program. Depicted ice particle had to be processed again, because there were overlapping pictures of ice particle, as shown in figure 3 (a). Separation was carried out by program, as shown in figure 3 (b). After separation, the picture was outlined to identify actual shape of ice particle and calculated mean diameter, as shown in figure $3(\mathrm{c})$.

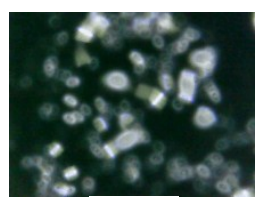

(a)

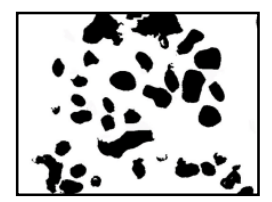

(b)

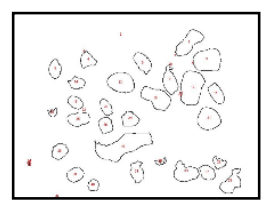

(c)
Fig 3. (a) Microscope Image (b) Detailed image (c) Outlined image 


\section{Results and Discussion}

\subsection{Initial Concentration Effect}

Figure 4 shows the relationship between temperature of solutions and time as a sample from the experimental results. The initial concentration of seawater was $1,1.5$, 2, 2.5 and $3 \mathrm{wt} \%$. Temperature data is recorded when low pressure of refrigerant was set at 2 bar. The temperature decreases with time, and this trend is similar as that obtained by Liu [20] and Sahagian [21]. The initial temperature of seawater and pure water drops fast until $0{ }^{\circ} \mathrm{C}$. That condition is caused by metastable or nonequilibrium state of seawater, which is so-called supercooling stage. $1 \mathrm{wt} \%$ of seawater need 25 minutes to reach supercooling stage. The rest can be described in the previous way, like 35 minutes for the $1.5 \mathrm{wt} \%, 36$ minutes for the $2 \mathrm{wt} \%, 36.5$ minutes for the $2.5 \mathrm{wt} \%$, and 39 minutes for the $3 \mathrm{wt} \%$. However, pure water did not experience supercooling stage because the particles tend to form solid substance.

After temperature of seawater descends to the supercooling stage, temperature is slight recover from $0{ }^{\circ} \mathrm{C}$ to $-2^{\circ} \mathrm{C}$ which caused by nucleation of ice particle. That condition can be called as nucleation stage where the latent heat released from the solid ice to the liquid is more than the heat removed from the system. Therefore, in this stage, the temperature fluctuates to a certain value and begin to form ice slurry particles. at a concentration of $1 \mathrm{wt} \%$, it only takes 25 minutes to form ice slurry particle and then followed by other concentrations.

Due to the Natrium Chloride content in seawater which act as freezing point depressant, the whole temperature and freezing point of seawater tends lower than pure water's. as described previously, the experiment result is reliable to study the correlation between concentrations and temperature.

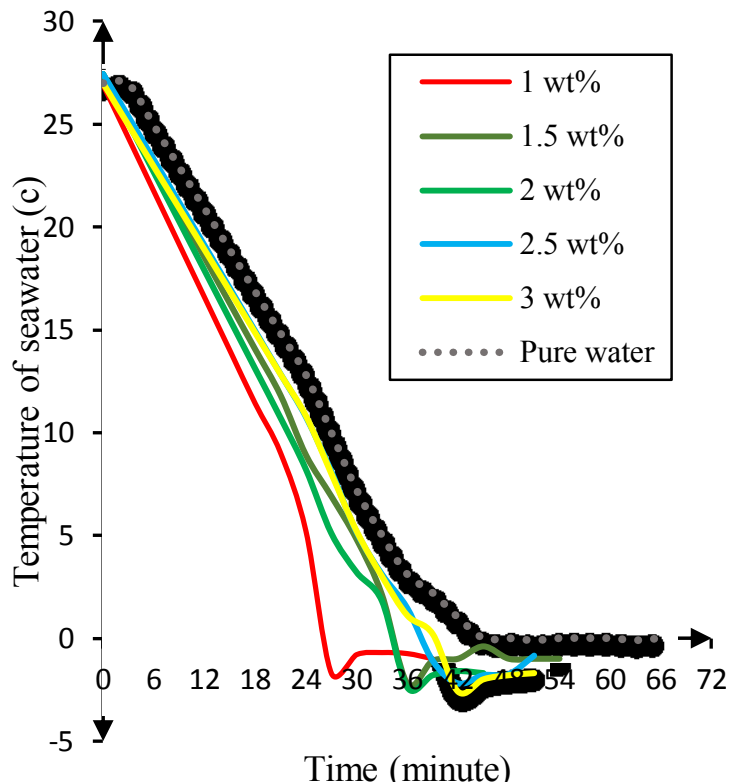

Fig 4. The temperature change of seawater and pure water

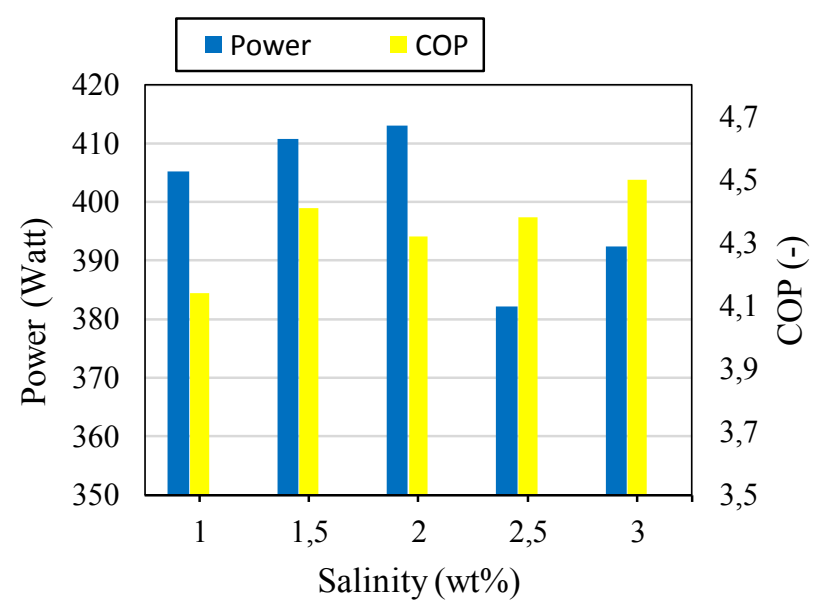

Fig 5. Performance of the examined ice slurry system for variation of initial concentration

The performance of the ice slurry system is then studied for power consumption and COP. In this study, it is assumed that the vapor-compression cycle of ice slurry system is ideal cycle. The cooling capacity in evaporator $Q_{\text {evap }}$, power consumption $W_{i n}$, and COP of the system are given by equation (1), (2) and (3) respectively:

$$
\begin{aligned}
& \mathrm{Q}_{\text {evap }}=\mathrm{h}_{\mathrm{g}, \mathrm{LP}}-\mathrm{h}_{\mathrm{f}, \mathrm{HP}} \\
& \mathrm{W}_{\text {in }}=\mathrm{h}_{\mathrm{OC}}-\mathrm{h}_{\mathrm{g}, \mathrm{LP}} \\
& \mathrm{COP}=\frac{\mathrm{Q}_{\text {evap }}}{\mathrm{W}_{\text {in }}}
\end{aligned}
$$

Where $h_{g, L P}, \quad h_{f, H P}$, and $h_{O C}$ represent the enthalpy $(\mathrm{kJ} / \mathrm{kg})$ of saturated gas at low pressure, the enthalpy of saturated liquid at high pressure and the enthalpy at outlet compressor, respectively.

The results are presented in Figure 5. It can be seen that the system presents the best performance at 3\% salinity whereby power consumption is only 392 Watt and COP is 4.5. This is because, during cooling process, $3 \%$ salinity have the lowest temperature, as depicted in figure 4 . Therefore, the rate of heat removal from the solution will increase and so does COP.

The effect of pump flow rate and scraper rotation was determined with variation of initial concentration of 1 , $1.5,2,2.5$ and $3 \mathrm{wt} \%$, respectively, as shown in Figure 6. At $\mathrm{x}$ axis that represent pump flow rate and scraper rotation variation, value one is represent as low speed condition (pump $=100\left[\mathrm{~m}^{3} / \mathrm{min}\right]$ and scraper $=350$ [RPM]), value two represent as medium speed condition (pump $=120\left[\mathrm{~m}^{3} / \mathrm{min}\right]$ and scraper $=450[\mathrm{RPM}]$ ), value three represent as high speed condition (pump $=130$ $\left[\mathrm{m}^{3} / \mathrm{min}\right]$ and scraper $\left.=550[\mathrm{RPM}]\right)$, respectively.

The ice production rate decreased as pump flow rate and scraper rotation the increased. However, when the pump flow rate and scraper rotation are kept in low speed condition, the ice slurry in evaporator will agglomerate [22]. At $1 \mathrm{wt} \%$ initial concentration, there was a drastic reduction in ice production against the increase in pump flow rate and scraper rotation. It is also 
shown that $1 \mathrm{wt} \%$ initial concentration produces the more ice production compared to others.

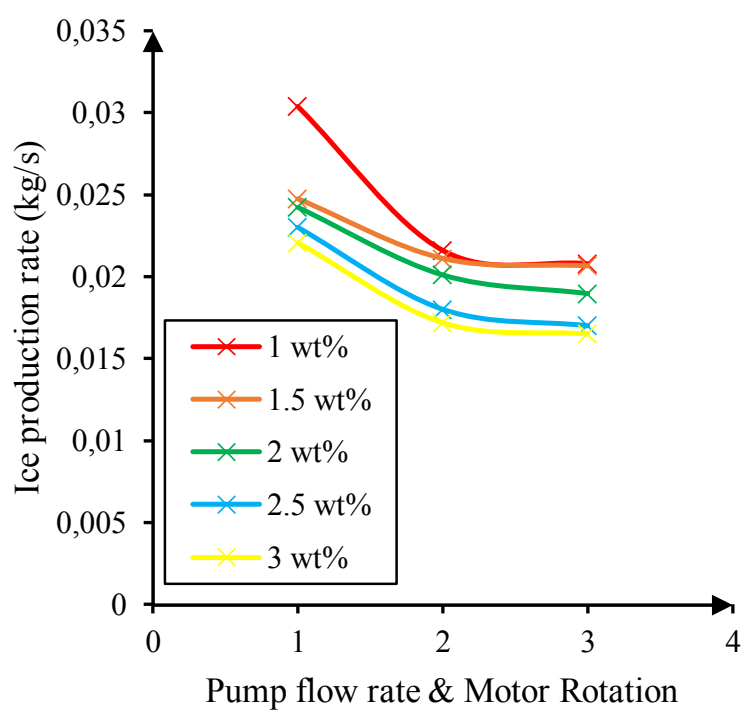

Fig 6. Effect of pump flow rate \& scraper rotation to ice production rate

\subsection{Observation Microscopy of Ice Slurry}

A conventional microscopic method can be used to study ice particle distribution. although when observing ice particle with microscope, there is a heat effect from environment that enter into the ice slurry. Furthermore, the disadvantage of microscopic method is only projected two-dimensional photograph. consequently, observing with two-dimensional projections rather than a full volume projection leads to a loss of information.

The result photographs from microscope show that the shape of ice particle is approximately ellipsoidal. Moreover, the solid particles of ice slurry are distributed in the carrier fluid, randomly (see figure 3a). Sari et al. [16] also reported that the shape of ice slurry is ellipsoid. The more ellipsoidal the ice particles, the more adequate to clarify the ice particles dimensions in terms of the ice diameter. The ice diameter is defined as follow in equation (4):

$$
D_{i}=\sqrt{\frac{4 A_{p}}{\pi}}
$$

Where $A_{p}$ represent area $\left(\mathrm{mm}^{2}\right)$ projection of photograph from ice slurry particle.

Depicted photographs of ice slurry have been statistically evaluated. The results of these observation are shown in Figure 7. Conventionally, ice slurry has particle dimension among 30-300 $\mu \mathrm{m}$, as reported by Kauffeld et al. [23], Fukusako et al. [24], Sari et al. [16] and Hansen et al. [18]. In contrast to what we found that ice slurry particle with seawater is millimeter in size. These contrast results relate to the previous research that generally using glycol or ethanol for observing ice particle, but this research using seawater.
It can be seen in Figure 7 that low concentration (1 $\mathrm{wt} \%$ ) results smallest ice particle. Generator also

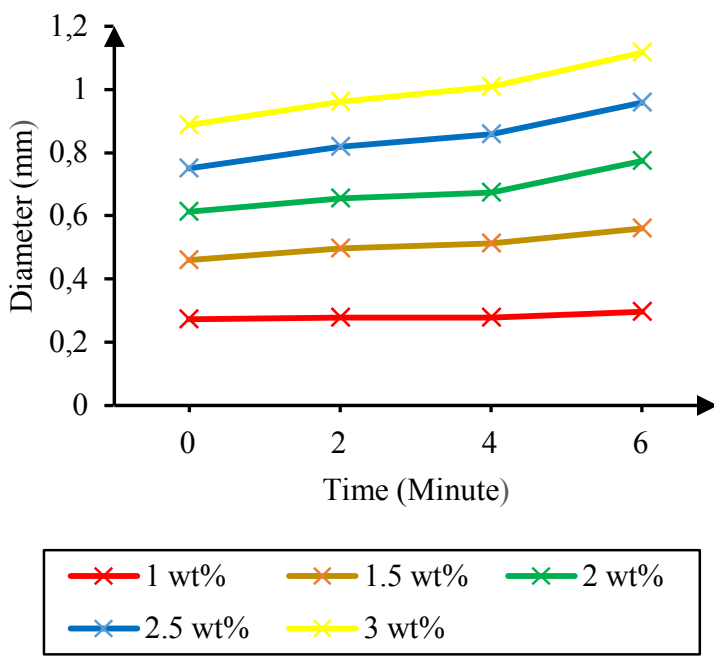

Fig 7. Ice particles growth to ice slurry production

influence the diameter of ice particle when he longer the ice generator operates the larger the dimeter is formed. Ice particle diameter grow dependency on Natrium Chloride content in seawater.

In order to illustrate the growth over time of the ice crystal size, the ice diameter can be correlated with a common form of polynomial second order equation, which may be defined as equation (5). this equation is expected to be used to predict the growth of ice particles. The growth rate can be defined at the time derivative of the ice diameter that formulated as equation (6). This method is similar to experiments that performed by Hansen et al. [18].

$$
\begin{gathered}
D_{i}=A x^{n}+B x+C \\
\frac{d\left(D_{i}\right)}{d t}=A n x^{(n-1)}+B
\end{gathered}
$$

Where A, B and C (-) represent as coefficient correlation of curve fitting and $\mathrm{x}$ represents time change as independent variable.

It can be seen that the diameter size of ice slurry increases along with increasing the initial concentration of seawater. This trend is the same as that found in past studies by Kitanovski et al. [25]. The higher the initial concentration of additive, the boundary layer between the ice particles will become increasingly tight [18]. Therefore, $3 \mathrm{wt} \%$ concentration shows the largest particle diameter compared with other concentrations. That is caused many particles that blend with each other. Table 2 summarizes the coefficient correlation from Figure 7 with coefficient determination $\left(R^{2}\right)$.

Ice mass fraction is the ratio between solid mass particle and total mass of ice slurry. there is difficulty in separating solid particles and liquid partcle of ice slurry, simultaneously. Therefore, there are many approaches in calculating ice fraction. Melinder [26] used the density approach to the function of temperature, so that the ice 
fraction can be calculated. Hansen [18] and Sari [16] calculated ice mass fraction from volume that obtained from microscopy picture ice slurry with assuming thickness of ice. In this study, it was assumed that the ratio of the area between the solid particles and the liquid particles depicted by the microscope represents the ice fraction, as shown in equation 7.

$$
X_{i}=\frac{m_{i}}{m_{1}+m_{i}} \cong \frac{A_{i}}{A_{1}+A_{i}}
$$

Where $m_{i}$ and $m_{l}$ (gr) represent as solid mass and liquid mass of ice slurry, respectively. $A_{i}$ and $A_{1}\left(\mathrm{~mm}^{2}\right)$ represent as solid area and liquid area of ice slurry depicted from microscope, respectively.

Table 2. Coefficient correlation of diameter ice particle

\begin{tabular}{|c|c|c|c|c|c|}
\hline $\begin{array}{c}\text { Initial } \\
\text { Concentration }\end{array}$ & $\mathrm{A}$ & $\mathrm{n}$ & $\mathrm{B}$ & $\mathrm{C}$ & $R^{2}$ \\
\hline $1.0 \%$ & 0.0029 & 2 & -0079 & 0.279 & 0.913 \\
\hline $1.5 \%$ & 0.0003 & 2 & 0.022 & 0.166 & 0.986 \\
\hline $2.0 \%$ & 0.0015 & 2 & 0.0005 & 0.159 & 0.982 \\
\hline $2.5 \%$ & 0.0011 & 2 & -0.038 & 0.181 & 0.940 \\
\hline $3.0 \%$ & 0.0001 & 2 & 0.006 & 0.130 & 0.978 \\
\hline
\end{tabular}

Figure 7 shows the effect of the concentration on the ice mass fraction. Low concentration $(1 \mathrm{wt} \%)$ yields the highest fraction that implies more formed solid particles than liquid particles. It can be seen that increasing the concentration, so the lower the ice mass fraction is produced. However, with a high mass fraction cause ice slurry more difficult to flow.

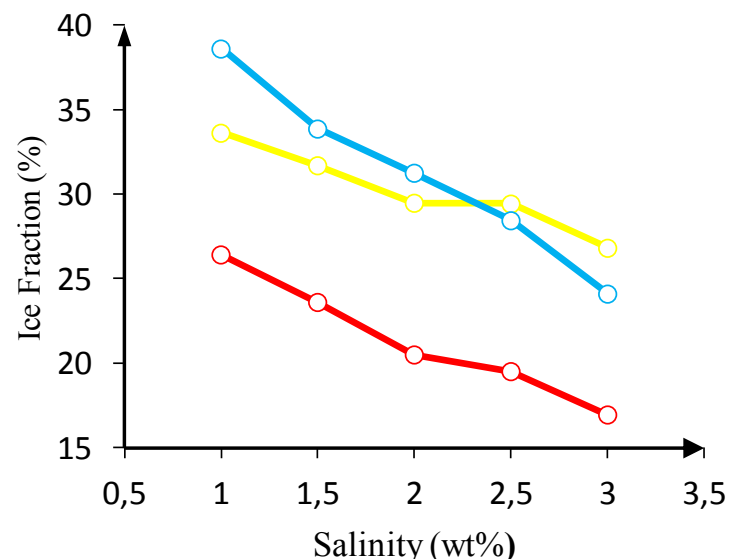

$$
\begin{aligned}
& \text { - Pump } 100 \mathrm{~m}^{\wedge} 3 / \min \& \text { Scraper } 350 \mathrm{RPM} \\
& -\mathrm{O} \text {-Pump } 120 \mathrm{~m}^{\wedge} 3 / \mathrm{min} \& \text { Scraper } 450 \mathrm{RPM} \\
& -\mathrm{O}-\text { Pump } 130 \mathrm{~m}^{\wedge} 3 / \mathrm{min} \& \text { Scraper } 550 \mathrm{RPM}
\end{aligned}
$$

Fig 7. Effect of salinity to ice mass fraction
Pump flow rate and scraper rotation indicate that low speed $\left(\right.$ pump $=100\left[\mathrm{~m}^{3} / \mathrm{min}\right]$ and scraper $\left.=350[\mathrm{RPM}]\right)$ will produce low ice mass fraction (see Figure 7). Between medium (pump $=120\left[\mathrm{~m}^{3} / \mathrm{min}\right]$ and scraper= 450 [RPM]) and high (pump $=130\left[\mathrm{~m}^{3} / \mathrm{min}\right]$ and scraper $=550[\mathrm{RPM}]$ ) speeds produce larger ice fractions and exhibit similar data trends, simultaneously. This explains the results of figure 6 that shows the higher the pump flow rate and the scraper rotation, the lower ice production rate.

\section{Conclusion}

The effect of initial seawater concentration on forming ice slurry was investigated experimentally. Ice slurry was produced by ice generator using scraper, and the initial seawater solution concentration was varied as an experimental parameter. According to the foregoing investigation it was found that the temperature ice slurry is time dependant. It appeared that the faster temperature drop of seawater at a higher initial concentration. this was caused to change in size of ice crystals. Results from the experimental data also reveal higher power consumption and COP (Coefficient of Performance) for low seawater concentrations.

The ice crystals in storage tank were observed by optical microscopy. It was found that ice crystal tends to be practically ellipsoidal. Therefore, its shape can be approached by circular geometry. The geometrical size of the ice particles grows along with the operating time of the ice generator. It showed that the smaller ice particle followed by higher initial concentration of solution. Value of ice fraction that seen directly by microscope showed good results. Variations speed of pump and scraper showed no significant contribution in the change of ice particles. The ice crystal is cannot easily be controlled. The knowledge of ice particle can be useful for optimal thermal storage in fishery industry.

Finally, this study could help the fishery industry to keep the freshness aquatic product and fulfil the need of thermal energy storage.

The authors want to thank RISTEK DIKTI for funding this work with grant PDUPT, No: 391/UN2.R3.1/HKP05.00/2018.

\section{References}

1. F. Shahidi. Pro. Fr. Se. Spr. 171-93 (1994)

2. G.M. Pigott, B.W. Tucker, Sci. op. Food. Re. Int. 3, 105-38 (1987)

3. I. Ashie, J. Smith, B. Simpson, N.F. Haard, Spoil. shelf. ext. Food. Sci. Nut. 36, 87-121 (1996)

4. J.J. MATSUMOTO 1980: ACS Publications)xx

5. L. Ababouch, L. Souibri, K. Rhaliby, O. Ouahdi, M. Battal, F. Busta, Qua. cha. sar. Food. Micro. 13, 123-32 (1996)

6. B. Ben-Gigirey, J.M.V.B. de Sousa, T.G. Villa, J. Barros-Velazquez, Cha. biog. amine. Int. J. Food. Micro. 57, 19-31 (2000) 
7. S. Baixas-Nogueras, S. Bover-Cid, T. VecianaNogués M.C. Vidal-Carou, Chem. Sen. Chan. J. agri. food. chem. 50, 6504-10 (2002)

8. F. Billiard, D. Viard, Food Safety. (In: FAO/WHO Global Forum of Food Safety Regulators Marrakech, Morocco, 28-30, 2002)

9. M. Kauffeld, M. Kawaji P.W. Egolf, Handbook on ice slurries (International Institute of Refrigeration, Paris 359, 2005)

10. P.W. Egolf, M. Kauffeld, Fr. phys. prop. Int. J. R. 28, 4-12 (2005)

11. M. Kauffeld, M. Wang, V. Goldstein, K. Kasza, Ic. slur. appl. Int. J. R. 33, 1491-505 (2010)

12. B. Frei, H. Huber, Char. diff. pum. Int. J. R. 28, 92-7 (2005)

13. M. Wang, T. Hansen, M. Kauffeld, K. Christensen, V. Goldstein, Slur. ic. Inf. fi. Int. 2, 42-46 (2000)

14. A. Melinder, M. Ignatowicz, Prop. sea. Int. j. of r. 52, 51-8 (2015)

15. A.S. Pamitran, H.D. Ardiansyah, M. Novviali, A. Re. Pa. Trans. Tech. 388, 128-32 (2013)

16. O. Sari, D. Vuarnoz, F. Meili, P.W. Egolf, Vis. ic. slur. 25-6 (2000)

17. Yanuar, Gunawan, M. Baqi, Char. Dra. Redu. J. Tek. 58, 95-9 (2012)

18. T.M. Hansen, M. Radosevic, M. Kauffeld, T. Zwieg, Inv. ic. cry. H. R. R. 9 19-32 (2003)

19. F.A. Rayhan, A.S. Pamitran, Perf. Ic. Slur. I. J. Tech. 8, (2017)

20. S. Liu, L. Hao, X. Guo, Z. Rao, Exp. st. Energy Proc. 75, 1445-51 (2015)

21. M.E. Sahagian, H.D. Goff, Fund. asp. fre. f. sci. T. 1-50 (1996)

22. H. Inaba, T. Inada, A. Horibe, H. Suzuki, H. Usui, Pre. aggl. gro. Int. J. R. 28, 20-6 (2005)

23. M. Kauffeld, K.G. Christensen, S. Lund T.M. Hansen, Ex. ic. slur. (In: Proc. of the 1st workshop on Ice Slurries, Yverdon-les-Bains, Switzerland, 1999)

24. S. Fukusako, Y. Kozawa, M. Yamada, M. Tanino, Re. dev. act. (In: Proceedings of the First Workshop on Ice Slurries of the International Institute of Refrigeration, pp 83105 1999)

25. A. Kitanovski, D. Vuarnoz, D. Ata-Caesar, P.W. Egolf, T.M. Hansen, C. Doetsch, T. flu. dyn. Int. J. R. 28, 37-50 (2005)

26. Å. Melinder, Ther. prop. aqu. (2007) 